\title{
Prediction of physiological exertion in hot environments using the JOS-2 thermoregulation model
}

\author{
Akihisa Nomoto $^{1, *}$, Yoshito Takahashi ${ }^{1}$, Yoshiichi Ozeki ${ }^{2}$, Masayuki Ogata ${ }^{1}$, and Shin-ichi Tanabe ${ }^{1}$ \\ ${ }^{1}$ Department of Architecture, Waseda University, Japan \\ ${ }^{2}$ AGC, Ltd., Innovative Technology Research Center, Japan
}

\begin{abstract}
In recent years, the outdoor summer environment in Japan has become progressively warmer due to the severity of the heat island phenomenon. The danger of heat stroke and thermal comfort outdoors in summer are regarded as problems. In order to evaluate these problems, it is important to evaluate physiological exertion in the human body. The purpose of this research is to demonstrate the possibility of predicting physiological exertion in the human body with high accuracy in an outdoor environment during summer using the JOS-2 thermoregulation model developed by our research group. First, the Japanese metabolic rate in summer and autumn was measured for various activities, including sitting, standing, and walking. As a result, we found that the metabolic rate during sitting and standing was lower by about $10 \%$ in summer than in autumn. Next, using the obtained metabolic rate measurement as an input to the model, the experiment in an outdoor environment during summer was reproduced using JOS-2. The accuracy of the predicted mean skin temperature and local skin wettedness in an outdoor environment during summer was improved by choosing the appropriate input to the model.
\end{abstract}

\section{Introduction}

Due to the severity of the heat island phenomenon, the outdoor environment in Japan during summer has become progressively warmer. In the background of the Tokyo Olympic in 2020 and the Expo to be held in 2025, the summer environment and thermal comfort outdoors in Japan must be improved. An evaluation based on human physiological exertion is important in order to evaluate the hot environment and thermal comfort.

The purpose of this research is to demonstrate the possibility of predicting physiological exertion with high accuracy in an outdoor environment during summer using the JOS-2 thermoregulation model[1]. First, the experimental value of human physiological exertion obtained in an outdoor environment during summer was compared with the values predicted with JOS-2. As a result, the values predicted with JOS-2 for skin temperature and local skin wettedness were higher than the experimental values. It was considered that the metabolic rate input into JOS-2 was high.

Metabolic rate which is one of the inputs of JOS-2 was used experimental values from Japanese subjects reported in a previous publication[2]. However, the seasonal and gender differences in metabolic rate and unsteady changes in metabolic rate due to activity changes are not taken into consideration. Thus, the inputs into the model should be corrected as improper inputs may be one cause of simulation error.

Although experiments in prior Japanese studies measuring metabolic rate focusing on seasonal differences and metabolic rate measurements were gathered for each activity level[3], few studies measured the metabolic rate alongside seasonal, gender, and activity level differences. Hence, there are no useful experiment data that can be used as the input into JOS-2.

\section{Metabolic rate measurement}

\subsection{Experiment outline}

The metabolic rate measurement experiment was conducted during the summer and autumn seasons of 2018 at the Tokyo Metropolitan Industrial Technology Research Institute.

Figure 1 shows the experimental procedure. Subjects walked for 15 minutes at a mean walking speed of 4.5 $\mathrm{km} / \mathrm{h}$ using a treadmill after resting for 40 minutes in a climate chamber and subsequently remained standing for 15 minutes. The air temperature in the climate chamber was set to the radiation temperature $\left(26^{\circ} \mathrm{C}\right)$; the relative humidity was set to $50 \%$ and the air velocity was set to $0.1 \mathrm{~m} / \mathrm{s}$.

Fig. 1. The experimental procedure

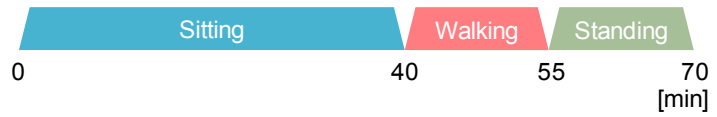

Table 1 shows the number of subjects for each activity and Table 2 shows data for the various subjects. The subjects were healthy young men and women. 14

\footnotetext{
* Corresponding author: nomoto@tanabe.arch.waseda.ac.jp
} 
subjects were examined during sitting (9 male, 5 females), 8 during walking (4 male, 4 females), and 10 during standing ( 9 male, 4 females). The subjects wore specified clothing (white polo shirt, underwear, gray slacks, socks, and shoes) in order to account for the thermal resistance of their clothing.

Table 1. The number of subjects for each activity

\begin{tabular}{lccccc}
\hline \multirow{2}{*}{ Posture } & \multicolumn{2}{c}{ Male } & \multicolumn{2}{c}{ Female } & \multirow{2}{*}{ Sum } \\
& Summer & Autumn & Summer & Autumn & \\
\hline \hline Sitting & 5 & 4 & - & 5 & 14 \\
Walking & - & 4 & - & 4 & 8 \\
Standing & 2 & 4 & - & 4 & 10 \\
\hline
\end{tabular}

Table 2. Subject data (mean $\pm \mathrm{SD})$

\begin{tabular}{lcccc}
\hline Gender & Height $[\mathrm{m}]$ & Weight $[\mathrm{kg}]$ & $\mathrm{BSA}^{*}[\mathrm{~m} 2]$ & BMR $^{* \star}[\mathrm{kcal} / \mathrm{day}]$ \\
\hline \hline Male & $1.75( \pm 0.09)$ & $68.7( \pm 9.9)$ & $1.84( \pm 0.17)$ & $1659( \pm 206)$ \\
Female & $1.58( \pm 0.08)$ & $54.1( \pm 8.9)$ & $1.55( \pm 0.18)$ & $1210( \pm 146)$ \\
\hline${ }^{*}$ Body Surface Area $\left[\mathrm{m}^{2}\right]$ (Calculated using Takahira's formula) \\
${ }^{* *}$ Basal Metabolic Rate $[\mathrm{kcal} /$ day]
\end{tabular}

\subsection{Measurements}

Table 3 shows the measurements gathered during the experiment. Regarding the thermal environment, the air temperature and the relative humidity were measured at multiple points using a thermometer in order to check differences in the vertical temperature distribution in the climate chamber. In addition, the radiation environment and airflow were measured using an amenity meter.

Regarding the physiological amount, subjects selfdeclared their height before starting the experiment. Their basal metabolic rate and body weight were measured using a body composition meter. In addition, during the experiments, gases exhaled from the subjects were sampled using a Douglas bag and gas analysis was performed using a VO2000 portable metabolic testing system. The metabolic rate was calculated from the mean value of oxygen consumption and carbon dioxide production every 3 breaths. Equation (1) was used to calculate the metabolic rate[4].

Table 3. List of measurements

\begin{tabular}{|c|c|c|c|}
\hline Items & & Position & Equipment \\
\hline $\begin{array}{l}\text { Air temp. } \\
\text { Relative humiodty }\end{array}$ & $\begin{array}{l}{\left[{ }^{\circ} \mathrm{C}\right]} \\
{[\%]}\end{array}$ & $\begin{array}{c}\mathrm{FL}+0.1,0.6,1.1 \\
1.7,2.2,2.7 \mathrm{~m}\end{array}$ & $\begin{array}{c}\text { Thermometer } \\
\text { (ESPEC RSW-20S) }\end{array}$ \\
\hline $\begin{array}{l}\text { Mean radiant temp. } \\
\text { Air velocity }\end{array}$ & $\begin{array}{r}{\left[{ }^{\circ} \mathrm{C}\right]} \\
{[\mathrm{m} / \mathrm{s}]} \\
\end{array}$ & $\mathrm{FL}+0.6 \mathrm{~m}$ & $\begin{array}{c}\text { Amenity meter } \\
\text { (AM101) }\end{array}$ \\
\hline $\begin{array}{l}\text { Basal metabolic rate } \\
\text { Weight }\end{array}$ & $\begin{array}{r}{[\mathrm{kcal} / \mathrm{day}]} \\
{[\mathrm{kg}]}\end{array}$ & & $\begin{array}{l}\text { Body composition meter } \\
\text { (TANITA innerscan DUAL) }\end{array}$ \\
\hline $\begin{array}{l}\mathrm{O}_{2} \text { consumption } \\
\mathrm{CO}_{2} \text { production }\end{array}$ & $\begin{array}{l}{[\mathrm{L} / \mathrm{min}]} \\
{[\mathrm{L} / \mathrm{min}]}\end{array}$ & & $\begin{array}{l}\text { Metabolic testing system } \\
\text { (VO2000) }\end{array}$ \\
\hline
\end{tabular}

$$
M=\frac{21(0.23 R Q+0.77) V O_{2}}{B S A}
$$

$\begin{array}{ll}M & : \text { Metabolic rate }\left[\mathrm{W} / \mathrm{m}^{2}\right] \\ V O_{2} & : \text { Oxygen consumption }[\mathrm{L} / \mathrm{min}] \\ R Q & : \text { Respiratory quotient ; a ratio of } V \mathrm{CO}_{2} \text { to } \\ & V O_{2} \text { [unitless] } \\ B S A & : \text { Body surface area }\left[\mathrm{m}^{2}\right] \\ & \text { (Calculated using Takahira's formula) }\end{array}$

\subsection{Experimental results}

\subsubsection{Thermal environment}

Table 4 shows measurements of the thermal environment. The results show the experimental values averaged over 2 days. The air temperature in the climate chamber was $25.8{ }^{\circ} \mathrm{C}$, the relative humidity was $51 \%$, the mean radiant temperature was $25.9{ }^{\circ} \mathrm{C}$, and the air velocity was $0.28 \mathrm{~m} / \mathrm{s}$. In this experiment, the subject walked on the treadmill, so the air velocity had no effect on the walking speed. In addition, it was confirmed that the difference in the vertical temperature distribution was extremely small, and the climate chamber was nearly as consistent as the thermal environment.

Table 4. Thermal environment measurements (mean $\pm \mathrm{SD})$

\begin{tabular}{cccc}
\hline $\begin{array}{c}\text { Air temp. } \\
{\left[{ }^{\circ} \mathrm{C}\right]}\end{array}$ & $\begin{array}{c}\text { Relative humidty } \\
{[\%]}\end{array}$ & $\begin{array}{c}\text { Air velocity } \\
{[\mathrm{m} / \mathrm{s}]}\end{array}$ & $\begin{array}{r}\text { Mean radiant temp. } \\
{\left[{ }^{\circ} \mathrm{C}\right]}\end{array}$ \\
\hline \hline $25.8( \pm 0.08)$ & $51( \pm 0.34)$ & $0.28( \pm 0.05)$ & $25.9( \pm 0.13)$ \\
\hline \multirow{2}{*}{ Difference of vertical temp. is $\pm 0.01\left[{ }^{\circ} \mathrm{C}\right]$}
\end{tabular}

\subsubsection{Metabolic rate}

Table 5 shows the metabolic rate measurements. The mean value for each subject's activity was 0.99 met during sitting, 1.07 met during standing, and 3.95 met during walking. Data outside 1.5 times the interquartile range were defined as outliers.

The metabolic rate measured while sitting during summer was 0.81 met, whereas the measured metabolic rate while sitting during autumn was 1.09 met. Moreover the metabolic rate measured while standing during summer was 0.88 met, whereas the measured metabolic rate while standing during autumn was 1.11 met. A t-test with two specimens assuming homoscedasticity was performed to confirm the seasonal difference in the metabolic rate. In order to eliminate gender differences, the mean metabolic rate during sitting and standing for male subjects in summer and autumn were compared. As a result, it was found that there was a significant seasonal difference in the metabolic rate during sitting at a significance level of $1 \%$, and a significant seasonal difference in the metabolic rate during standing position at a significance level of $5 \%$.

In countries with four seasons, such as Japan, it is thought that changes in meal along with seasonal temperature fluctuations may cause seasonal differences in metabolic rate. However, the subjects of the summer and autumn experiments in this study are not the same, so the effects of individual differences are included. Hence, we plan to examine seasonal differences in metabolic rate by the same subject data and to increase the number of subjects in each season in future.

The same test as above was carried out to ascertain gender differences in the metabolic rate. In order to eliminate seasonal differences, the mean metabolic rate value for each activity for male and female subjects during autumn was compared. As a result, no significant differences were observed for any activity. 
Table 5. Metabolic rate measurements (mean \pm SD)

(a) Seasonal differences

\begin{tabular}{lccc}
\hline \multicolumn{1}{c}{ Posture } & \multicolumn{3}{c}{ Metabolic rate [met] } \\
& Summer & Autumn & t-test \\
\hline \hline Sitting & $0.81( \pm 0.07)$ & $1.09( \pm 0.06)$ & $* *$ \\
Standing & $0.88( \pm 0.04)$ & $1.11( \pm 0.06)$ & $*$ \\
Walking $(4.5 \mathrm{~km} / \mathrm{h})$ & - & $3.95( \pm 0.46)$ & - \\
\hline
\end{tabular}

(b) Gender differences

\begin{tabular}{lccc}
\hline \multicolumn{1}{c}{ Posture } & \multicolumn{3}{c}{ Metabolic rate [met] } \\
& Male & Female & t-test \\
\hline \hline Sitting & $1.00( \pm 0.06)$ & $1.10( \pm 0.05)$ & n.s \\
Standing & $1.08( \pm 0.06)$ & $1.10( \pm 0.15)$ & n.s \\
Walking $(4.5 \mathrm{~km} / \mathrm{h})$ & $4.08( \pm 0.45)$ & $3.85( \pm 0.19)$ & n.s \\
\hline n.s : not significant, & ${ }^{*}: \mathrm{p}<0.05$, & ${ }^{* *}:<0.01$ &
\end{tabular}

Equations (2) and (3) define the metabolic rate over time during the rising and decreasing phases, respectively. It is generally known that the metabolic rate exponentially increases or decreases until it reaches a steady state when human activity level changes. Therefore, continuous data on the metabolic rate is required to accurately reproduce an experiment in which the activity level changes.

$$
m(t)\left\{\begin{array}{l}
=m_{0}+\left(m_{1}-m_{0}\right)\left(1-e^{-a t}\right) \\
=m_{0}+\left(m_{1}-m_{0}\right) e^{-b t}
\end{array}\right.
$$

$\begin{array}{ll}t & : \text { Time }[\mathrm{s}] \\ m_{0} & : \text { Low metabolic rate }[\mathrm{met}] \\ m_{1} & : \text { High metabolic rate }[\mathrm{met}] \\ a, b & : \text { Rate constant }\left[\mathrm{s}^{-1}\right]\end{array}$

Fig. 2 shows changes in the metabolic rate. The experimental data was fit to a model using least squares regression. After an activity level change, the steady state was reached after approximately 5 minutes, thus the rate constant was regressed using data for the first 5 minutes after an activity level change. In addition, in order to eliminate seasonal differences, we only used data from 9 of the males and females who participated in the experiment during autumn. The rate constant was found to be 0.011 for the rising and falling phases.

Fig. 2. Metabolic rate changes over time
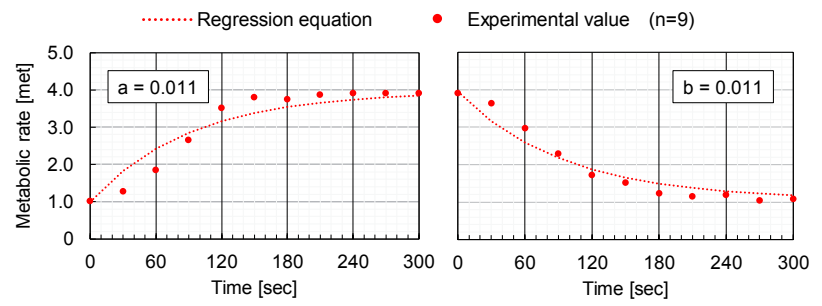

3 Prediction of physiological exertion in
an outdoor environment during summer
The experimental data gathered from subjects outdoors during summer is reproduced in this section using the metabolic rate determined in the previous section. In order to verify the accuracy of predicting skin temperature and local skin wettedness due to a changing metabolic rate, the experimental value and the predicted values from the model were compared.

\subsection{Experiment outline}

In order to collect physiological data on the human body during summer in an outdoor environment, an experiment was conducted at Waseda University at 10:00-12:00 and 13:00-15 00 on August 8-14, 2016.

Fig. 3 shows the experimental procedure. After staying in the pre-room for 30 minutes, the subject stayed outdoor under shade for 15 minutes and outdoor under solar radiation for 15 minutes. After walking 750 $\mathrm{m}$ around the campus, they stayed in climate chamber for 40 minutes. The air temperature in the front room was set to the mean radiation temperature $\left(26{ }^{\circ} \mathrm{C}\right)$; the relative humidity was set to $50 \%$ and the air velocity was set to $0.1 \mathrm{~m} / \mathrm{s}$. The air temperature in the climate chamber was set to the mean radiation temperature $\left(20^{\circ} \mathrm{C}\right)$; the relative humidity was set to $50 \%$ and the air velocity was set to $0.1 \mathrm{~m} / \mathrm{s}$.

The subjects were 10 young men. Physiological data such as local skin temperature and skin wettedness were measured during the experiment. The subjects wore specified clothing (white polo shirt, underwear, gray slacks, socks, and shoes) in order to account for the thermal resistance of their clothing.

Fig. 3. Experimental procedure

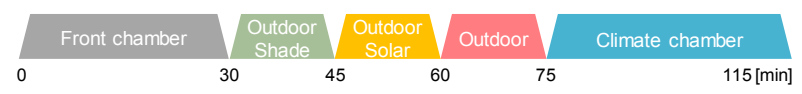

\subsection{Measurements}

Regarding the thermal environment, the air temperature, relative humidity, air velocity, and short and long wave radiation around the subject were measured by mounting measuring equipment on a cart.

Regarding physiological exertion, local skin temperature was measured at 11 points (head, neck, chest, back, pelvis, shoulder, arm, hand, thigh, leg, and foot), and near skin temperature and humidity were measured at 2 points (chest and back). Then mean skin temperature was calculated from the 7-point method and the local skin wettedness was also calculated.

\subsection{Simulation outline}

Table 6 shows the input conditions. Regarding the body conditions, mean value of all subjects was input into the model. The clo value was measured using a thermal manikin that was wearing the clothes used in the experiment, and the value at each body part was input into the model. 
The table shows the metabolic rate input before and after changes in activity level. The initial metabolic rate was 0.95 met during sitting, according to data from the literature[2]. The initial metabolic rate during standing and walking outdoors was determined from measurements gathered with an accelerometer worn on the subject's arm. However, since the arm does not move in the standing position, the validity of the measured value is uncertain. The new metabolic rate was 0.81 met while sitting and 0.88 met while standing, based on the experimental results shown above. However, since the walking speed during the metabolic rate measurement experiment and the outdoor experiment were different, the value measured with the accelerometer $(1.7 \mathrm{met})$ was used for walking. In addition, the change in metabolic rate was considered with the above rate constants $\mathrm{a}=\mathrm{b}=$ 0.011 when the activity level changes.

Table 6. Simulation inputs

(a) Experimental conditions

\begin{tabular}{|c|c|c|c|c|}
\hline & & Pre-room & Outdoor & Climate chamber \\
\hline Time & [min] & 1000 & 50 & 40 \\
\hline Air temp. & {$\left[{ }^{\circ} \mathrm{C}\right]$} & 26 & & 20 \\
\hline Mean radiant temp. & {$\left[{ }^{\circ} \mathrm{C}\right]$} & 26 & Measurement & 20 \\
\hline Relative humidity & [\%] & 50 & Value & 50 \\
\hline Air velocity & {$[\mathrm{m} / \mathrm{s}]$} & 0.1 & & 0.1 \\
\hline
\end{tabular}

(b) Body conditions

\begin{tabular}{lcc}
\hline Gender & male \\
Age & 23 \\
Height & {$[\mathrm{m}]$} & 1.76 \\
Weight & {$[\mathrm{kg}]$} & 66 \\
Fat & {$[\%]$} & 15 \\
\hline
\end{tabular}

(c) Metabolic rate conditions

\begin{tabular}{lccc}
\hline \multirow{2}{*}{ Posture } & \multicolumn{3}{c}{ Metabolic rate [met] } \\
& Before & & After \\
\hline \hline Sitting & 0.95 & $\rightarrow$ & 0.81 \\
Standing & 1.20 & $\rightarrow$ & 0.88 \\
Walking & 1.70 & $\rightarrow$ & 1.70 \\
\hline
\end{tabular}

(d) Clothing conditions

\begin{tabular}{lcc|lcc}
\hline Segment & $\begin{array}{c}\text { Clo value } \\
\text { [clo] }\end{array}$ & $\begin{array}{c}\text { Clothing } \\
\text { area [-] }\end{array}$ & Segment & $\begin{array}{c}\text { Clo value } \\
\text { [clo] }\end{array}$ & $\begin{array}{c}\text { Clothing } \\
\text { area [-] }\end{array}$ \\
\hline \hline Head & 0.60 & 1.11 & R-Shoulder & 0.56 & 1.11 \\
Neck & 0.06 & 1.01 & R-Arm & 0.00 & 1.00 \\
Chest & 1.09 & 1.16 & R-Hand & 0.00 & 1.00 \\
Back & 0.91 & 1.14 & L-Thigh & 0.57 & 1.11 \\
Pelvis & 1.34 & 1.18 & L-Leg & 0.77 & 1.13 \\
L-Shoulder & 0.56 & 1.11 & L-Foot & 0.77 & 1.13 \\
L-Arm & 0.00 & 1.00 & R-Thigh & 0.57 & 1.11 \\
L-Hand & 0.00 & 1.00 & R-Leg & 0.77 & 1.13 \\
& & & R-Foot & 0.77 & 1.13 \\
\hline
\end{tabular}

\subsection{Simulation results}

Fig. 4 shows a comparison between the experimental and predicted values. Regarding mean skin temperature, the predicted mean skin temperature before the set metabolic rate changes is higher than the experimental value, and it is close to the maximum value. Meanwhile, the mean skin temperature after the set metabolic rate value changes was predicted to be nearly the same as the experimental value, and it was confirmed that the prediction accuracy improved.

Regarding chest skin wettedness, in the pre-room environment, the both predicted value are near the minimum experimental value. In the outdoor environment, the predicted chest skin wettedness value before the metabolic rate changes was greater than the experimental value, whereas the predicted chest skin wettedness after the metabolic rate changes generally falls within the error range of the experimental value. However, both predicted values rapidly decreased immediately after entering the climate chamber, demonstrating a tendency that is different from the experimental value.

Fig. 4. Comparison between the experimental and predicted values

(a) Mean skin temperature

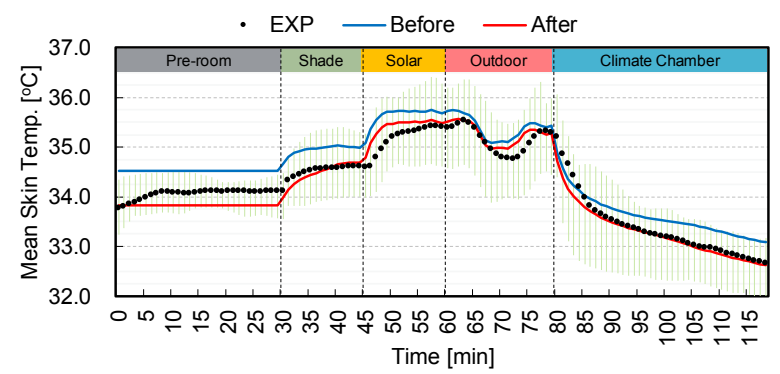

(b) Chest skin wettedness

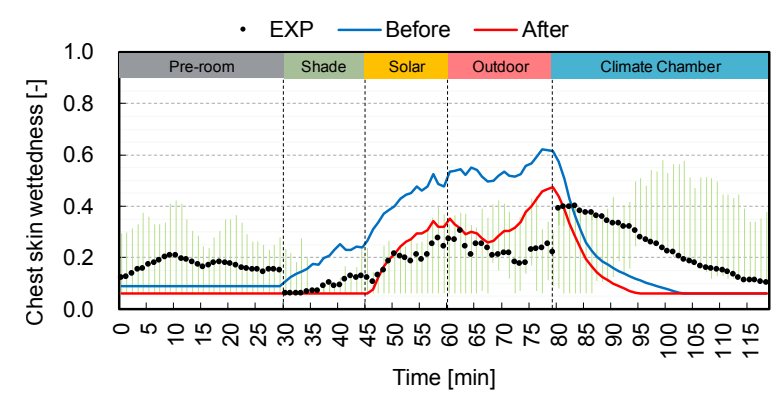

\section{Conclusion}

The Japanese metabolic rate in summer and autumn was measured for various activities, including sitting, standing, and walking. As a result, it was found that the metabolic rate during sitting and standing was lower by about $10 \%$ in summer than in autumn. Using the obtained metabolic rate measurement as an input to the JOS-2 thermoregulation model, the experiment in an outdoor environment during summer was reproduced using JOS-2. As a result, The accuracy of the predicted mean skin temperature and chest skin wettedness in an outdoor environment during summer was improved.

\section{References}

1. Y. Kobayashi et al., Building and Environment, 66, pp.1-10 (2013)

2. T. Ohnaka et al., J. Anthrop. Soc. Nippon, 90, pp.337-384 (1982)

3. K. Fukai et al., Transactions of the Society of Heating, Air-conditioning and Sanitary Engineers of Japan, 50, pp. 99-108 (1994)

4. Y. Nishi, Studies in Environmental Science,10, pp. 29-39 (1981) 